\title{
International Helgoland Symposium 1992 The centennial of the Biologische Anstalt Helgoland "The challenge to marine biology in a changing world"
}

\section{Congratulatory address of the Deutsche Zoologische Gesellschaft E. V.}

\author{
Prof. Dr. Dr. H.-R. Duncker \\ Institut für Anatomie und Zytobiologie; Aulweg 123, D-35392 Gießen, Germany
}

Honoured participants, Herr Direktor Gunkel, Herr Bürgermeister Baumann, Ladies and Gentlemen, dear Colleagues,

It is a great pleasure for me to express my congratulations on behalf of the German Zoological Society to the Biologische Anstalt Helgoland on the occasion of its 100th anniversary. The German Zoological Society, which is now 102 years old, together with the Botanical Society and the German Society of Natural Scientists and Physicans, was from the start instrumental in promoting the foundation of a Biological Station at Helgoland by the German Government as a general institution, unrelated to any specific university. Thus, the Biologische Anstalt Helgoland and the German Zoological Society have had a long, and successful co-existence, especially after the two World Wars. The vitality of the Biologische Anstalt and the scientific necessity for such a German Biological Station have been especially documented by its survival after the Second World War at List/Sylt, and by the impressive rebuilding of the Biologische Anstalt Helgoland in the 1950 s and later years.

This close connection with the Biological Station on Helgoland was always very important for German zoologists, and also for zoologists of neighbouring countries. Besides Naples, in Italy, Helgoland was the primary location where German zoologists could perform their marine biological investigations, including studies of taxonomy, comparative anatomy, ecology, physiology and geographical distribution of marine animals. Even before the establishment of the Biological Station, numerous eminent zoologists travelled to Helgoland in order to carry out their investigations. The Station has not only maintained its importance over 10 decades, but has even increased in value regarding these investigations, in these times where it has become increasingly difficult to obtain access to the various animals for all types of research - particularly considering 
the broad scope of topics investigated today, ranging from systematics to molecular biology and genetics.

In addition to being a site for ongoing research, the Biological Station has always been a location for fruitful scientific discussion and exchange among scientists. It has thus become an important meeting place for open and free scientific exchange at an international level. This is especially important for German zoologists today: due to heavy enrolments in our universities, as well as heavy teaching and administrative burdens, the teacher-scientist does not have the necessary environment for this kind of intensive exchange in a relaxed situation, where he or she can concentrate on scientific questions. Often deep friendships have originated from these cooperative undertakings at the Station, which are an important basis for further scientific communication and cooperation, especially beyond the borders of individual countries.

Another important activity of the Biological Station is its role in the teaching and education of students. Excursions to the Biological Station and laboratory courses there are an essential and important component of zoological studies. These courses are an integral part of their education, where students are exposed to the diversity of organisms, as well as to the multiplicity of their life histories and ecological situations. By direct observation and experience they learn to set up experiments with animals, using scientifically sound methods and techniques according to the present "state of the art". Courses of this kind make a lasting impression on students for their entire scientific life, and real zoologists should avail themselves of such an opportunity at least once during their studies.

In the past, the Biological Station has also had the task of collecting marine material and supplying different universities for investigation and laboratory courses. This has been a substantial task. A large number of courses depend on this material for direct investigation of living or preserved animals. Considering our present situation concerning the difficulty of obtaining material for laboratory courses, it will continue to be advantageous and helpful for the teaching of zoology, when this source of material remains available in the future.

A biological station such as the BAH on Helgoland gains additional and special importance due to its location regarding the survey and control of the ecological situation of the surrounding waters and endangered species. Not only the chemistry, but especially organisms and their behaviour and reproduction are the best indicators of pollution and also of the consequences for human life. For these reasons the Station, together with other institutions and research centres, has a special position in science today. Here, scientists working in the field of ecological control can best undertake the necessary long-term observations and measurements that will give us sufficient data to evaluate ecological changes and work out strategies for preserving our marine ecosystems - one of the most valuable resources of our country.

The German Zoologists would like to express their gratitude for 100 years of successful cooperation with the Biological Station, together with cordial wishes for continued development in the next hundred years, with the same intensity and activity. Science can prosper only by dynamic development of methods, techniques, and ideas. This is in direct correlation with the conditions under which these investigations are performed. Thus, we sincerely hope that the Biologische Anstalt Helgoland will be able to continue its scientific development, to be in a position to offer attractive working 
conditions for scientists and for the teaching of students. Science today can only survive with a healthy portion of international competition and cooperation. To maintain our place among the leaders of science in the world, we need attractive places for research and teaching in Germany, as Helgoland has been for the last hundred years. This will continue to attract scientists from all over the world and serve to facilitate a fruitful exchange among scientists and students.

At the moment, German zoologists are fearful of losing the legal basis to continue research on animals, which is the foundation for a qualitatively adequate and internationally competitive education in zoology. The already restrictive and very strict German Animal Protection Law is presently being revised and will lead to drastic restriction of all scientific investigations and especially for teaching students directly on animal material. Such a revised Animal Protection Law will also substantially inhibit research and practical education at the Biological Station. It will specifically hinder the education of the next generation of zoologists to deal competently with animals, with their care and protection. Thus, young zoologists cannot obtain the ability to maintain and handle animals prior to and during experimentation according to the proper "state of the art". If this reform overrides the practices put forth in the Animal Protection Law of 1986, we will lose our competence in science, and our international scientific role will fade away quickly and dramatically. Up to now, scientists have viewed Germany as an attractive country for scientific work.

To describe the direness of the situation, I would like to cite, with permission, a letter written by a member of the German Zoological Society, Steven Perry, after more than 15 years of scientific work at German institutes, and now working in a Canadian university. It was addressed to Minister Riesenhuber, who has already left the auditorium, in connection with this new Animal Protection law, and characterizes the situation ironically, but precisely:

"I was delighted to read recently that the animal protection law in Germany is going to be made more strict. In fact, it appears that zoological research - in particular physiological research - will become virtually impossible in Germany. This is indeed good news for us here in Canada.

The fact that the Nobel Prize was just awarded to two Germans for their development of the patch-clamp technique, which is now a basic tool in membrane physiology, speaks for the excellent quality of German basic research in an area that will now no longer be accessible there. Countries like Canada and the United States will certainly continue to profit to an even greater degree than at present from the emigration of disillusioned, but extremely capable, scientists from Germany. Indeed, this seems an excellent way to solve your problem of under-employment among academically-qualified persons, while at the same time saving millions by not having to equip expensive laboratories.

I am looking forward to seeing more of your scientists taking up residence in Canada. This will greatly improve our competitiveness while at the same time relieving Germany of any meaningful contribution to biomedical research."

On this occasion, I want also to appeal to our Minister for Research and Technology, to do everything in his power to help us retain the possibilty to perform scientific research in our fields of choice, to be able to continue fruitful collaborative investigations which in the past have given a number of German zoologists the opportunity to become worldwide leaders in their fields. The German Zoological Society has elaborated statements 
and comments on the proposed new animal protection law. We offer our willingness and expertise for further discussion, hoping for a scientifically constructive result from the legislation.

Biology will be the leading natural science in the next century, essential for a better understanding of the nature of the living world around us as well as of our own nature. Beyond this, biology will be the scientific field of greatest importance for our survival on earth. This type of biology will extend far beyond molecular biology, and will deal with the complex functional systems of organisms and their interactions with the environment. Biological observation and experimentation in the field will be of major importance in the future; thus, the essential role of biological stations such as Helgoland cannot be overestimated.

In the name of all German zoologists I sincerely wish the Biologische Anstalt Helgoland continued success in the coming century as a place of research for the zoological sciences, but also success in their endeavours to conserve our very endangered ecological world. 